\title{
Use of date palm fibers as reinforcement for thermoplastic-based composites
}

\author{
Noureddine MAHMOUdi ${ }^{1,2, a}$ \\ 1 Laboratory of numerical and experimental modelling of the mechanical phenomena, BP 882-RP, University of Mostaganem, \\ 27000 Mostaganem, Algeria \\ 2 University of Relizane, Beremadia, 48000 Relizane, Algeria
}

Received 13 July 2012, Accepted 18 December 2012

\begin{abstract}
The use of natural fibers in the development of composite materials is a sector in full expansion. These fibers were used for their low cost, their availability and their renewable character. The fibers of the palm (palm tree) were used as reinforcement in polypropylene (PP). The date palm fibers have some potential because of their ecological and economic interest. Both unmodified and compatibilized fibers are used. Compatibilization was carried out with the use of maleic anhydride copolymers. The morphology and mechanical properties were characterized by electron microscopy scanning (SEM) and tensile tests. The influence of fiber content on mechanical properties of composite $\mathrm{PP} /$ date palm has been evaluated and demonstrated, that the maximum stress and elongation decreases with increasing fiber volume rate. On the other hand, an increase of the tensile modulus has been noticed, but after the fibers improvement, the maximum stress increases significantly up to $25 \%$ weight.
\end{abstract}

Key words: Plant fiber / palm / SEM / compatibilizer

\section{Introduction}

In the field of composite materials, the polymer matrices strengthening by fibers was initially developed using the synthetic fibers and man-made fibers such as glass, carbon, aramid, etc. to take advantage of their high specific modulus [1]. During recent years, much work has been dedicated to natural fibers to replace man-made fibers [2]. Many reasons support this choice as their character renewability, biodegradability and their low density. Among the natural fibers that have undergone special attention, the fibers of kenaf [3], sisal [4], jute [5], and abaca [5], etc. were investigated.

Most composite materials used in different sectors are mainly manufactured using thermosetting matrices. The disadvantages arising from their use include the fragility, the durability and repair inability/or damaged parts recycling. These disadvantages have led to the development of thermoplastic composites.

By comparing with thermo-hardening, thermoplastics have a deformation at break greater, faster to melt and retain the ability to be recycled if necessary. Polypropylene (PP) is the first synthetic polymer that reaches industrial importance due to its low cost and high mechanical properties.

\footnotetext{
${ }^{a}$ Corresponding author: mahmoudi.noureddine@yahoo.fr
}

After each harvest season, the leaves of date palms rich in fiber are discarded or burned, except for that little quantity is used by the cottage industry. These fibers exhibit mechanical properties which can be used in technical areas, unlike vegetal fibers difficult to procure. The abundant availability of these fibers, natural biodegradability, neutrality towards $\mathrm{CO}_{2}$ emissions into the atmosphere and requiring little energy to be produced with a low bulk density and rate absorption of high water that exceeds $200 \%$, thus leaving more advantageous compared to other fibers. But after the results of Kriker [6], their tensile strength and elongation at break fall with time of immersion. These results are in agreement with those of Toledo et al. [7]. Protection fiber has been considered by treating the fiber and the change in its matrix [8].

Cellulose is the essential element in definition of resistance [9], the literature [3-6, 10-13] shows that the palm leaves fibers have rates cellulose and hemicellulose relatively low compared to those of sisal fibers. For cons, the rate of cellulose and lignin is similar to those of coco fibers.

Fung et al. [14] have shown that the incorporation of $10 \%$ by weight of sisal fibers improves the Young's modulus by $150 \%$ and the tensile strength of $10 \%$. Vilaseca et al. [15] showed that in the composites PP/abaca the tensile strength and Young's modulus increase with the 
increase of abaca. Therefore the rigidity of the composite, the elongation at break decreases significantly with the addition of abaca fibers. Bhattacharyya et al. [16] showed that the addition of wood fiber composite plates with polypropylene matrix improves the tensile modulus up to $250 \%$ with a mass fraction of $25-30 \%$ fiber.

Date palm fibers are used in many technical fields such as the field of buildings, infrastructure, furniture, packaging, boxes, rollover, sport, leisure and even in the automotive and aerospace, etc.

The aim of this study is studied the effect of adding the fibers of date palms in a polypropylene matrix on the mechanical behavior of this material.

\section{Experiment}

\subsection{Material}

The fibers used are vegetal fibers rushes date palm. These fibers have a light brown color and a circular section with a diameter ranging from 0.20 to $0.70 \mathrm{~mm}$, a density of $1540 \mathrm{~kg} \cdot \mathrm{m}^{-3}$ and a humidity of $10 \%$. The length of the fibers used is $10 \mathrm{~mm}$ and $0.5 \mathrm{~mm}$ wide. The fibers were obtained by grinding and screening date palm rushes. These fibers were then extracted in a Soxhlet at reflux with a solvent mixture acetone/ethanol $(75 / 25 \mathrm{v} / \mathrm{v})$. The fibers were then depigmented dried at $80{ }^{\circ} \mathrm{C}$ for $2 \mathrm{~h}$.

The thermoplastic polymer used in our study is polypropylene $(\mathrm{PP})$. It is in the form of granules white in color. Its density is 0.96 g. $\mathrm{cm}^{-3}$ and a flow index $\left(190{ }^{\circ} \mathrm{C} / 2.16 \mathrm{~kg}\right)$ of $40 \mathrm{~g} / 10 \mathrm{~min}$.

The coupling agent used for composites based on PP is PPgMA. The PPgMA OVERAC CA 100 is used to Atofina, with a flow index $10 \mathrm{~g} / 10 \mathrm{~min}$ and a density of 0.909 g.cm ${ }^{-3}$. PEgMA is a terpolymer of ethylene, vinyl acetate and maleic anhydride Atofina, containing less than $2 \%$ by weight of MA.

\subsection{Preparation of composites}

Date palm fibers are mixed with the PP using the compounding method "Micro-Compounder Xplore (DSM)". Mass fractions of several fibers (fibers of increasing proportions from $0 \%$ to $30 \%$ in steps of $5 \%$ ). Palm fibers and thermoplastic polymer were introduced into a mixing chamber with a speed of up to 40 rev. $\mathrm{min}^{-1}$ for $10 \mathrm{~min}$. After obtaining the mixture, a hot press is used to make test specimens. One takes a sufficient amount of the mixture and setting in a mold (form tensile specimens) trough the two faces, then pressing the material into the mold at a temperature of $130{ }^{\circ} \mathrm{C}$, gradually increasing the pressure up to 5 ton and expected distribution and dispersion of the material in the mold for $8 \mathrm{~min}$. In the end, press it cooled to $40{ }^{\circ} \mathrm{C}$ at the same pressure ( 5 tons) to give the tensile specimens according to ASTM D638. Tensile tests are performed using a INSTRON tensile testing machine at a loading rate of $0.5 \mathrm{~mm} \cdot \mathrm{min}^{-1}$.

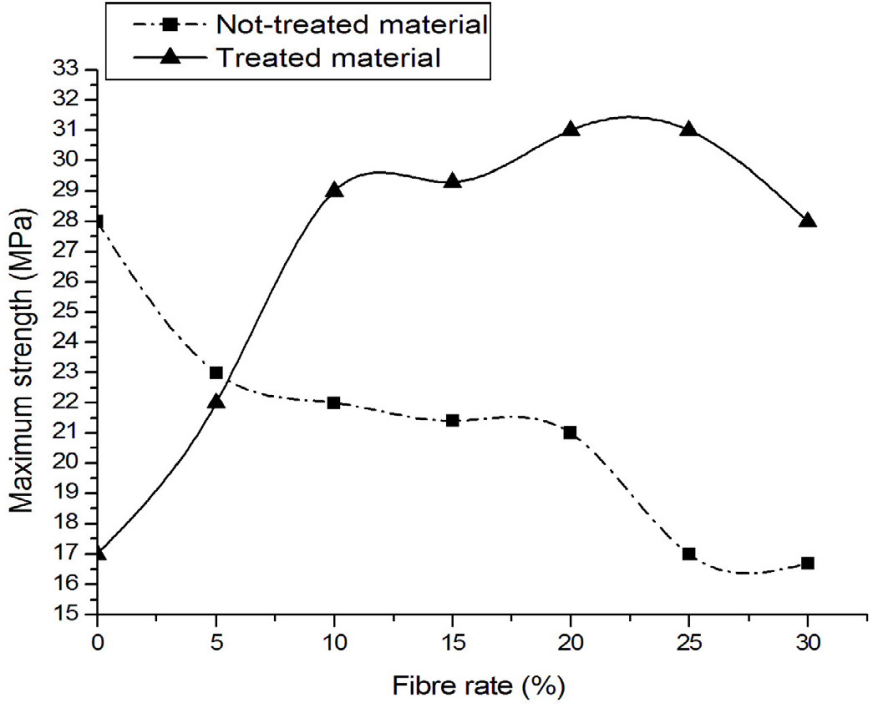

Fig. 1. Variation of the maximum strength according to the fiber rate.

The dry fibers of the palm and coupling agent were mixed with the thermoplastic matrix with different proportions (from 0 to $30 \%$ ) to study the effect of the amount of coupling agent on the properties of composite. The reinforcement content is chosen to $30 \%$ by weight and $10 \%$ by weight of the coupling agent quantity, based on the results obtained by Mutjé et al. [17].

The scanning electron microscopy (SEM) "JSM-5610" was used to study the morphology of the different materials and observe the interface reinforcement/matrix. The specimens were quenched in liquid nitrogen, broken, mounted on sample holder, coated with a solution of gold/palladium and observed using a voltage of $10 \mathrm{kV}$.

\section{Results and discussion}

\subsection{Effect of the date palm fibers addition}

Tensile tests were conducted by varying the rate of reinforcement at a speed of $0.5 \mathrm{~mm} \cdot \mathrm{min}^{-1}$ biasing. They showed that the addition of palm fibers of dates has changed the behavior of polypropylene.

Figure 1 shows the effect of the addition of polypropylene fibers (treated and not-treated) on the tensile properties of the composite.

The fiber reinforced palm dates (not-treated) showed a decrease of tensile strength by increasing the rate of reinforcement which is consistent with other researchers [18-20]. As the fiber content increases, the weak interfacial bonds of the surface of the fiber with the matrix increase, and therefore the tensile strength decreases.

Thwe et al. [18] showed that the decrease in tensile strength is attributed to the low adhesion between the fibers and the matrix, which promotes the formation of microcracks at the interface. High fiber content may cause the formation of porosities during injection, which leads 
to the formation of micro cracks during the test and subsequently the reduction of tensile strength.

Saturation of the reinforcement increases gradually with the progress of the resin front. In the case where saturation is not complete, there is then the presence of faults, called porosities. These are usually air bubbles trapped in the resin which combine to form air pockets and permanent, to a lesser extent, the gases dissolved in the resin [21]. Studies by Patel et al. [22] and Chen et al. [23] show that these porosities can be microscopic in size and take place in the strands, or can be of macroscopic size and then find between the strands. The percentage of porosities and their distribution can be linked to several parameters intrinsic material and injection: the viscosity and the capillary pressure of the resin, the reinforcement porosity and the front resin local speed. Experimental studies show that the resin front speed is an essential mechanism of impregnation of the reinforcement. So when the resin front velocity is low, the capillary forces dominate over viscous forces. This leads to a preferential progression in the resin inside the wicks of the reinforcement and therefore the creation of macroporosities between these wicks. In the opposite case, for a high speed front, the capillary forces are negligible compared to viscous forces. The resin envelops the strands without having to impregnate the time, resulting in the formation of micro porosities between the fibers within the strands.

The fiber-reinforced composites resistance depends on the degree in which the applied load is transmitted to the fibers. If the fibers are short with respect to their critical length, the fibers up out of the requested matrix composite breaks and for low loads. The tensile strength of all composites studied is less than that of polypropylene because they made no treatment to improve the adhesion between the fibers and the matrix [24]. The ultimate stress of each composite depends on several factors; the main ones are the properties of the reinforcement, matrix and fiber volume fraction. The fibers mechanical properties, as the initial modulus and tensile strength, are related not only to the fibers chemical composition but also to their internal structure [25].

Several strategies were discussed to improve adhesion between the fillers and the polymer matrix [26]. Modification of fibers and/or matrix is made by physical and chemical methods. The simplest method is the use of graft copolymers based on maleic anhydride, such as maleated polypropylene as compatibilizing agent to improve the interfacial compatibility. Improvements in mechanical properties and moisture resistance are generally obtained when maleinized copolymers are used as counting [27-30]. The maleated polypropylene was used as compatibilizing agent for the various PP-based composite as organic matrix.

\subsection{Effect of the addition of date palm fibers after adding the coupling agent}

Figure 1 also shows us the evolution of the maximum stress as a function of volume fraction fibers treated by

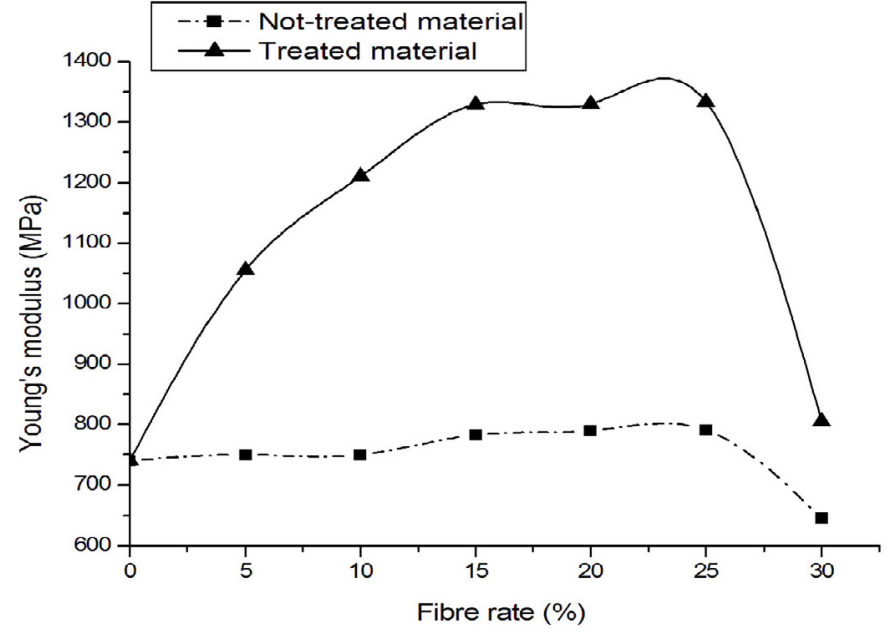

Fig. 2. Variation of the Young modulus according to the fiber rate.

the compatibilizer, for reinforced composites with $30 \%$ by weight of fibers. Note that the maximum stress increases with increasing reinforcement rate, which allows us to say that the introduction of compatibilizer in the formulation leads to improved mechanical properties. This improvement is attributed to better adhesion obtained following the introduction of the coupling agent which results in better stress transfer between the $\mathrm{PP}$ matrix and reinforcements. However, it is clearly observed the existence of a critical content of compatibilizer, between 5 and $25 \mathrm{wt} \%$, beyond which there is a decrease of the stress. The amount of compatibilizer is probably sufficient to coat the fibers. The excess of compatibilizer acts as a plasticizer for the system.

Figure 1 also shows that the maximum stress for the treated material is lower than that for the non-treated material from $0 \%$ to $5 \%$, due to the importance of the amount of the resin malleable. Starting from $5 \%$, the maximum stress increases to the excess over the untreated materials maximum stress, agreeing well with the theory of the laws of mixtures.

\subsection{Young's modulus}

Figure 2 shows that the Young's modulus increases with increasing weight percentage of fibers incorporated for both materials (treated and not-treated), for during tension loading porosities were created partially separated, which blocked the stress propagation between the fibers and the matrix [31]. When the fiber fraction increases, the degree of blockage increases, which consequently increases the stiffness [24], which is consistent with other researchers $[18-20,32]$ and theoretical predictions of the laws of mixtures, according to Andonian et al. [33], the Young's modulus depends on the Young's modulus of the matrix and that of the fibers. This finding is also justified by works of Khenfer and Morlier [34]. 


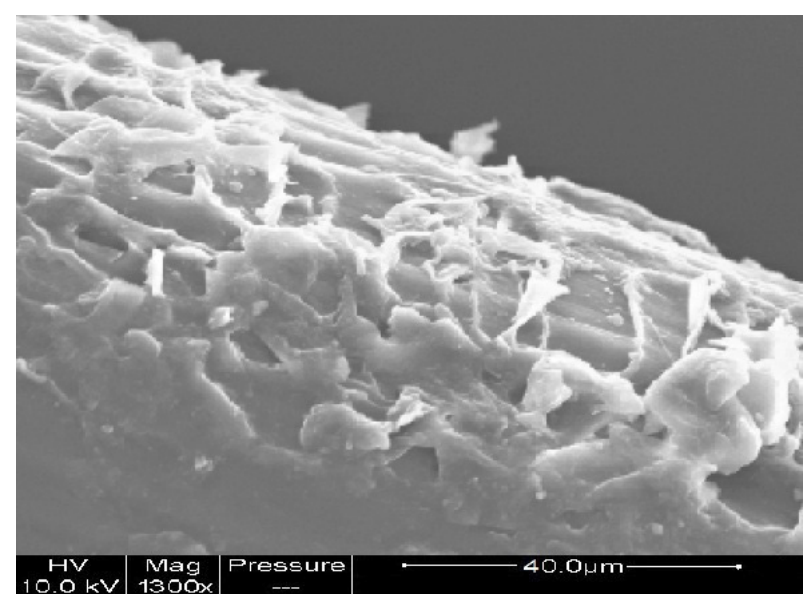

Fig. 3. Observation of the texture of fiber of the palm tree by SEM.

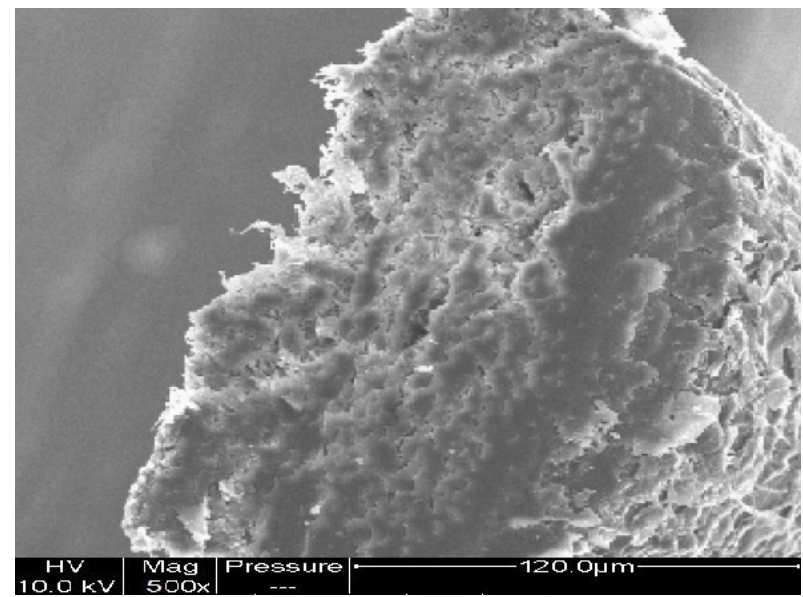

Fig. 4. Transverse section of fiber of the palm tree under SEM $(120 \mu \mathrm{m})$.

\section{Study of microstructure}

\subsection{Fiber texture}

The examination of the texture of the fibers used by SEM is presented in Figures 3 to 7.

Figure 3 shows the texture of the fiber, the diffraction of fiber by X-ray powder claims the palm fiber is amorphous. Figure 4 shows the cross section of the fiber used indicating rigid cross section, unlike cellulose fibers which have a hollow section [34].

Bledzki and Gassan [35], in their study of plant fibers, have noticed that the resistance depends on the spiral filaments form; they find that the wide spiral fibers have high deformability, but a low resistance, while the fibers have a low angle spiral low deformability and resistance. Fiber date palm has a solid section (poor spiral angles) with respect to flax fibers containing a large angle.

The actions of the man and the machines, in the agroindustrial transformations, multiply of defects for some fibers like flax [36]. Then, during the processing of textile surfaces many defects appear and there is an amplification of their volume. Then the defects are largely

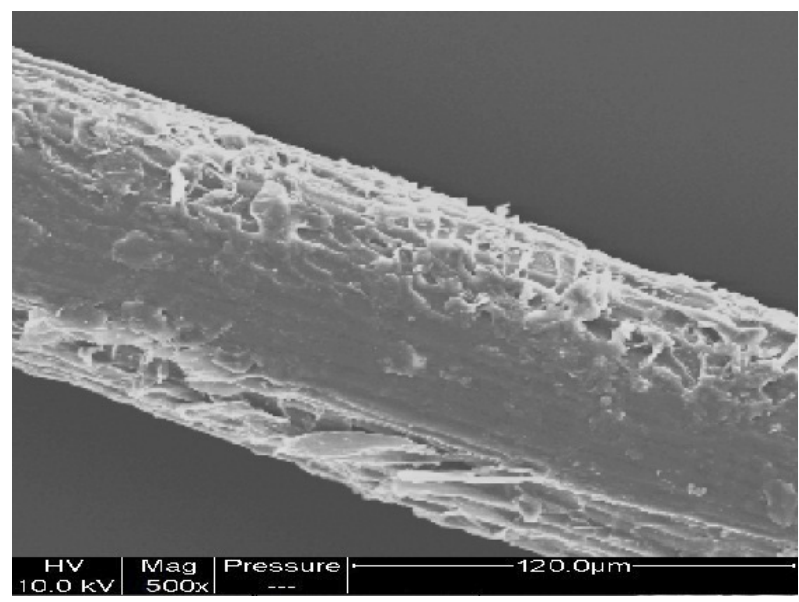

Fig. 5. Longitudinal section of fiber of the palm tree under SEM.

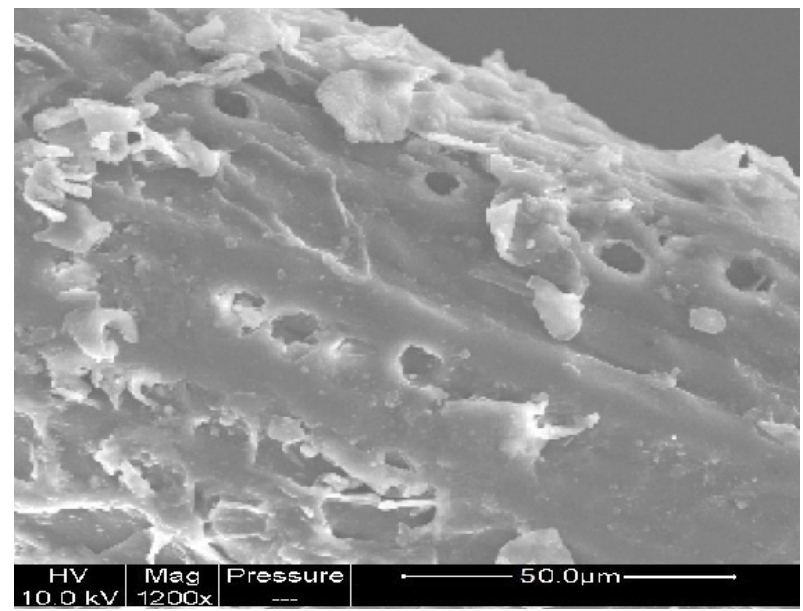

Fig. 6. Observation of the pores in fiber of the palm tree by SEM.

responsible for the mechanical characteristics heterogeneity of the vegetal fibers and causing ruptures of fibers during mechanical solicitations, but in the case of date palm fibers their preparation is simple which reduces defects.

Figure 5 shows that the fiber consists of very small filaments containing a set of slips (in the form of pages of books) oriented in the longitudinal direction. The presence of the pores in the fiber has advantages and disadvantages, among the advantages pore structure contributes to better adhesion between the fiber and the matrix, as the resin enters the pores, thereby increasing the material properties, but the presence of humidity in the pores decreases the fiber properties over time [6-37], then the protection of the fibers has been considered by treating the fiber and the matrix modification to decrease the degradation of the fibers properties [8].

The disordered sheets allow the flexibility of the filament. In addition there is the presence of some pores in the fiber which shows it is hydrophilic (Fig. 6). According to Figure 7, the fiber has tangles, which provides good fiber-matrix adhesion. 


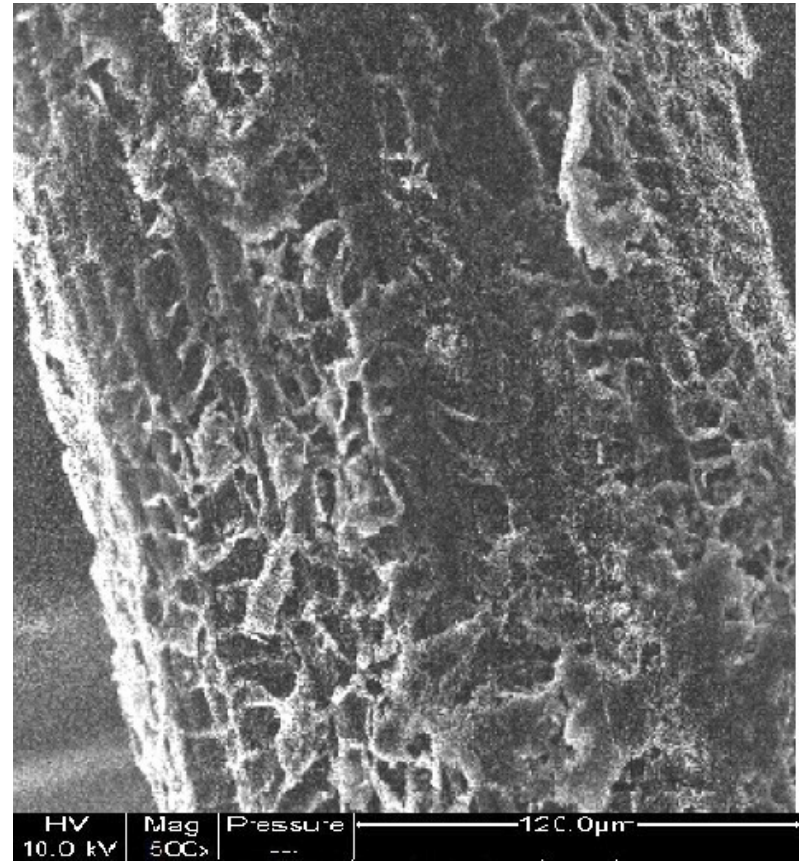

Fig. 7. Observation of a tangential sight of fiber of the palm tree by SEM.

\subsection{The face fiber-matrix}

Figures $8 \mathrm{a}-\mathrm{c}$ show the SEM micrographs performed on fracture surfaces of composites based on PP. For nonreinforced materials, that is the thermoplastic matrix (polypropylene) (Fig. 8a), the fracture surface is rather smooth indicating a brittle fracture of polymers.

The SEM micrographs for composites containing unmodified fibers, shown in Figure 8b clearly indicate that the adhesion between the fibers and polymer matrix is low. This is clearly demonstrated by the absence of any physical contact between the two components. The fibers are extracted from the thermoplastic matrix after rupture of the material. On the other hand, the rupture of samples failed to break the fibers of date palms, it is clearly observed the appearance of porosities in the form of holes due to loosening of the matrix fibers. The low polarity of the thermoplastic matrix and the high surface energy of cellulose fibers are responsible for the lack of compatibility and lack of contact between the matrix and reinforcement.

In contrast, for modified composites that is for which the coupling agent was introduced by SEM analyzes show that these agents improve the adhesion between polymer matrix and the fibers of palm (Fig. 8c). Based on these observations by SEM, it is likely to obtain better mechanical properties for composites in which the coupling agent is introduced.

\section{Conclusion}

In this work, a development of matrix composite reinforced polypropylene date palm was made, the effect

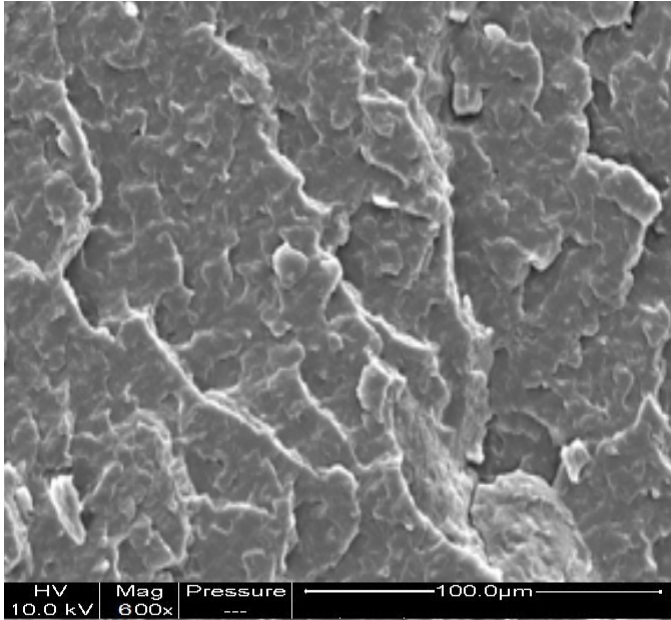

(a)

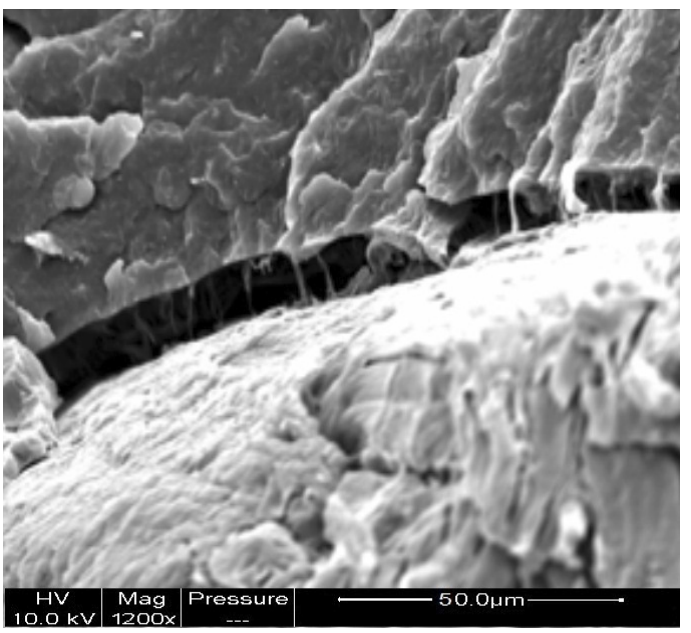

(b)

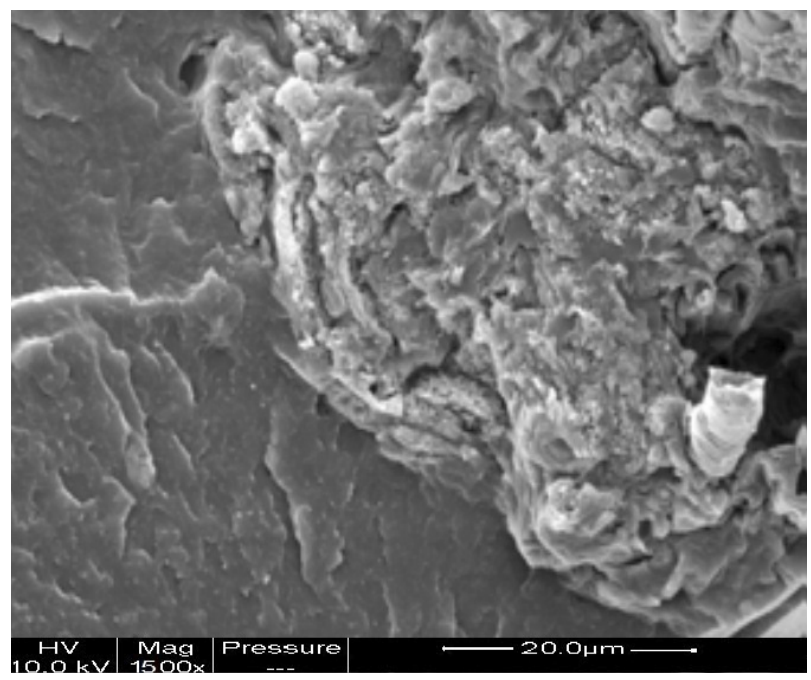

(c)

Fig. 8. SEM of the coldly broken composite material surface with matrix polyethylene at low density with (a) $0 \%$ in weight, (b) $20 \%$ in fiber weight of leaflets of the date palm and (c) $30 \%$ in fiber weight in the presence of $10 \%$ of polyethylene grafted maleic anhydride (PEgMA). 
of the addition of fiber composite and coupling agent on the tensile mechanical properties of the composites also studied. A study of microstructure was carried out by scanning electron microscope.

The following remarks can be drawn:

- considering the mechanical properties, the addition of non-modified fibers did not improve the maximum tensile strength;

- the introduction of the coupling agent improves the mechanical properties;

The Young's modulus of the composite continues to increase with increase in the rate of reinforcement in the composite improved;

- the date palm plant fibers have an amorphous texture;

- in addition, they have a solid section and have the same constituents as the wood;

- the presence of entanglements on their surfaces of the fibers provides good adhesion fiber-matrix.

Acknowledgements. The author of the present work wishes to thank Relizane University staff for their financial support. I also dedicate this humble work to the memory of my father. A special thanks to my mother, my wife without whom this work would not have been and my children (Amine and Mustafa).

\section{References}

[1] P.V. Joseph, K. Joseph, S. Thomas, Effect of processing variables on the mechanical properties of sisalfiber-reinforced polypropylene composites, Compos. Sci. Technol. 59 (1999) 1625-1640 http://dx.doi.org/10. 1016/S0266-3538(99) 00024-X

[2] R.T. Woodhams, G. Thomas, D.K. Rodgers, Wood fibers as reinforcing fillers for polyolefins, Polym. Eng. Sci. 24 (1984) 1166-1171

[3] M. Zampaloni, F. Pourboghrat, S.A. Yankovich, B.N. Rodgers, J. Moore, L.T. Drzal, A.K. Mohanty, M. Misra, Kenaf natural fiber reinforced polypropylene composites: A discussion on manufacturing problems and solutions, Compos.: Part A 38 (2007) 1569-1580 http://dx.doi. org/10.1016/j.compositesa.2007.01.001

[4] K.L. Fung, X.S. Xing, R.K.Y. Li, S.C. Tjong, Y.W. Mai, An investigation on the processing of sisal fibre reinforced polypropylene composites, Compos. Sci. Technol. 63 (2003) 1255-1258 http://dx.doi.org/10. 1016/S0266-3538(03) 00095-2

[5] A.K. Bledzki, A.A. Mamun, O. Faruk, Abaca fibre reinforced PP composites and comparison with jute and flax fibre PP composites, Express Polym. Lett. 1 (2007) $755-762$

[6] A. Kriker, G. Debicki, A. Bali, M.M. Khenfer, M. Chabannet, Mechanical properties of date palm fibres and concrete reinforced with date palm fibres in hot-dry climate, Cement Concrete Compos. (2005) 554-564

[7] F.R.D. Tolëdo, K. scrivener, G. England, K. Ghavami, Durability of alkali-sensitive sisal and coconut fibers in cement mortar composites, Cement Concrete Compos. 22 (2OOO) 127-143

[8] H. Gram, Durability of natural fibers in concrete, Swedish Cement Concrete Res. 83 (1983) 255
[9] A.K. Bledzki, J. Gassan, Composites reinforced with cellulose based fibers, Progress polym. Sci. 24 (1999) 221274

[10] L. Nilson, Reinforced Concrete with Sisal and other vegetal fibre, Swedish Council for Building Research, 1975

[11] T.S.R. Ayyar, P.K. Mirihagalla, Elephant grass fibers and reinforcing fiber, Magazine Concrete Res. 28 (1976) 16267

[12] R.S.P. Coutts, Flax fibers as a reinforcement in cement mortar, Int. J. Cement Compos. Lightweight Concrete 5 (1983) 257-262

[13] F.R.D. Tolëdo, K. Ghavami, D. Englan, K. Scrivener, Development of vegetal fibres-mortar composites of improved durability, Cement Concrete Compos. 25 (2003) 12

[14] K.L. Fung, X.S. Xing, R.K.Y. Li, S.C. Tjong, Y.-W. Mai, An investigation on the processing of sisal fibre reinforced polypropylene composites, Compos. Sci. Technol. 63 (2003) 1255-1258 http://dx.doi.org/10. 1016/S0266-3538(03)00095-2

[15] D. Bhattacharyya, M. Bowis, K. Jayaraman, Thermoforming wood fibre-polypropylene composite sheets, Compos. Sci. Technol. 63 (2003) 353-365 http://dx.doi.org/10.1016/S0266-3538(02) 00214-2

[16] F. Vilaseca, A.V. Gonzalez, P.J.H. Franco, M.A. Pèlach, J.P. López, P. Mutjé, Biocomposites from abaca strands and polypropylene, Part I: Evaluation of the tensile properties, Bioresource Technology 101 (2010) 387-395

[17] P. Mutjé, A. Lopez, M.E. Vallejos, J.P. Lopez, F.Vilaseca, Full exploitation of cannabis sativa as reinforcement/filler of thermoplastic composite materials, Composites: Part A 38 (2007) 369

[18] M.M. Thwe, K. Liao, Effects of environmental aging on the mechanical properties of bamboo-glass fiber reinforced polymer matrix hybrid composites, Composites: Part A 33 (2002) 43-52 http://dx.doi.org/10.1016/ S1359-835X (01) 00071-9

[19] A.K. Rana, A. Mandal, S. Bandyopadhyay, Short jute fiber reinforced polypropylene composites: effect of compatibiliser, impact modifier and fiber loading, Compos. Sci. Technol. 63 (2003) 801-806 http://dx.doi.org/10. 1016/S0266-3538(02) 00267-1

[20] F. Vilaseca, J.A. Mendez, A. Pelach, M. Llop, N. Canigueral, J. Girones, X. Turon, P. Mutje, Composite materials derived from biodegradable starch polymer and jute strands, Process Biochem. 42 (2007) 329-334

[21] K.M. Pillai, Modeling the unsaturated flow in liquid composite molding processes: A review and some thoughts, J. Compos. Mater. 38 (2004) 2097-2118

[22] N. Patel, V. Rohatgi, L.J. Lee, Micro scale flow behavior and void formation mechanism during impregnation through a unidirectional stitched fiberglass mat, J. Compos. Mater. 35 (1995) 837-851

[23] Y.-T, Chen, C.W. Macosko, H.T. Davis, Wetting of fiber mats for composites manufacturing: II. Air entrapment model, J. Compos. Mater. 41 (1995) 2274-2281

[24] Md. Rezaur Rahman, Md. Monimul Huque, Md. Nazrul Islam, Mahbub Hasan, Improvement of physicomechanical properties of jute fiber reinforced polypropylene composites by post-treatment, Composites: Part A 39 (2008) $1739-1747$ 
[25] P. Wambua, J. Ivens, I. Verpoest, Natural fibres: can they replace glass in fibre reinforced plastics, Compos. Sci. Technol. 63 (2003) 1259-1264 http://dx.doi.org/ 10.1016/S0266-3538(03)00096-4

[26] M.N. Belgacem, A. Gandini, The surface modification of cellulose fibres for use as reinforcing elements in composite materials, Compos. Inter. 12 (2005) 41 http://dx. doi.org/10.1590/S0104-14282005000200010

[27] M.N. Anglès, J. Salvado, A. Dufresne, Steam-exploded residual softwood-filled polypropylene composites, J. Appl. Polym. Sci. 74 (1999) 1962

[28] D.F. Caulfield, D. Feng, S. Prabawa, R.A. Young, A.R. Sanadi, Interphase effects on the mechanical and physical aspects of natural fiber composites, Die Angewandte Makromolekulare Chemie 272 (1999) 57

[29] M.E. Malainine, M. Mahrouz, M.A. Dufresne, Lignocellulosic flour from cladodes of Opuntia ficusindica reinforced polypropylene composites, Macromol. Mater. Eng. 289 (2004) 855

[30] H. Faria, N. Cordeiro, M.N. Belgacem, A. Dufresne, Dwarf Cavendish as a source of natural fibers in poly(propylene)-based composites, Macromol. Mat. Eng. 291 (2006) 16
[31] H. Ismail, M. Edyhan, B. Wirjosentono, Bamboo fiber filled natural rubber composites: the effects of filler loading and bonding agent, Polymer Testing 21 (2002) 39-144

[32] S. Joseph, M.S. Sreekala, Z. Oommen, P. Koshy, S. Thomas, A comparison of mechanical properties of phenol formaldehyde composites reinforced with banana fibers and glass fibers, Compos. Sci. Technol. 62 (2002) $1857-1868$

[33] A.L. Andonian, Y.W. Mai, B. Cotterell, Strength and fracture properties of cellulose fibers reinforced cement composites, Int. J. Cement Compos. Lightwigh Concrete 11 (1979) 151-158

[34] M.M. Khenfer, P. Morlier, Effet de la longueur des fibres sur les propriétés mécaniques des ciments renforcés de fibres cellulosiques, Mater. Struct. (1991) 185-190

[35] A.K. Bledzki, J. Gassan, Composites reinforced with cellulose based fibers, Progress Polym. Sci. 24 (1999) 221274

[36] M. Sotton, Perspectives de développement textiles et technique de lin, Journées d'échanges Franco-Allemands sur le lin, Rouen, 1992

[37] F.A.L. Dullien, Porous media: fluid transport and pore structure, second edition, 1995, 48, B37-B37 